\title{
PERFORMA PRODUKSI KEBUN KELAPA SAWIT RAKYAT PADA DATARAN TINGGI
}

\author{
Posman HP Marpaung ${ }^{1}$, Fandri Siburian ${ }^{2}$, Tulus Fernando Silitonga ${ }^{3}$ \\ ${ }^{12) 3)}$ Dosen Fakultas Pertanian Universitas Quality. \\ Email : posman123@gmail.com
}

\begin{abstract}
Keterbatasan lahan mineral sebagai lahan produktif membuat sebagian masyarakat melakukan ekspansi budidaya kelapa sawit menuju lahan gambut pada kondisi kelas marginal (Kelas S3). Ekspansi kebun sawit menuju lahan gambut diiringi dengan Peraturan Pemerintah Nomor 57 tahun 2016 tentang Perlindungan dan Pengelolaan Ekosistem Gambut. Regulasi tersebut berdapak positif untuk melindungi dan mengembalikan fungsi hidrologis gambut, namun berpengaruh pula terhadap pengelolaan budidaya kelapa sawit tersebut.

Keterbatasan lahan gambut juga membuat sebagian masyarakat beralih menggunakan dataran tinggi sebagai bentuk ekstensifikasi pertanian dan perkebunan. Penanaman kelapa sawit pada dataran tinggi merupakan bentuk ekspansi budidaya kelapa sawit yang terbatas akibat kurangnya ketersediaan lahan yang cukup. Perlu dilakukan kultur teknis dan kebutuhan biaya (cost) yang "lebih" agar diperoleh produksi yang sama meyerupai perlakuan kultur teknis kelapa sawit pada kondisi lahan kelas sangat sesuai (Kelas S1).

Beberapa perusahan negara sudah melakukan penanaman kelapa sawit pada dataran tinggi. Bahkan sebagian lokasi kebun perusahaan negara telah melakukan konversi menjadi kelapa sawit dari tanaman perkebunan lainnya. Hal ini tentu akan sangat berbeda jika dilakukan oleh para petani (smallholder) yang berada di dataran tinggi. Pengetahuan petani akan kultur teknis serta tingginya dana yang akan digunakan untuk budidaya tanaman kelapa sawit menjadi faktor penghambat selain dari faktor kelas lahan yang marginal.
\end{abstract}

Keywords : Kelapa sawit; dataran tinggi; produktivitas.

\begin{abstract}
The limitation of mineral land as a productive land makes some people expand oil palm cultivation to peat land in marginal class conditions (Class S3). The expansion of oil palm plantations into peatlands is accompanied by Government Regulation No. 57 of 2016 concerning Protection and Management of Peat Ecosystems. The regulation has a positive effect to protect and restore the hydrological function of peat, but also affects the management of oil palm cultivation.

The limitation of peatlands also makes some people switch to using the highlands as a form of agricultural and plantation extensification. Planting oil palms in the highlands is a form of expansion of oil palm cultivation that is limited due to lack of sufficient land availability. It is necessary to carry out technical culture and cost requirements that are "more" in order to obtain the same production resembling the treatment of oil palm technical culture in very suitable class land conditions (Class S1).

Some state-owned companies have planted oil palms in the highlands. Some state-owned plantation sites have even been converted to oil palm from other plantation crops. This will certainly be very different if done by farmers (smallholders) who are in the highlands. Farmers' knowledge of technical culture and the high amount of funds that will be used to cultivate oil palms are an inhibiting factor other than marginal land class.
\end{abstract}

Keywords: Palm oil; plateau; productivity. 


\section{PENDAHULUAN}

Keterbatasan lahan produktif menyebabkan ekstensifikasi pertanian/perkebunan mengarah pada lahan marginal seperti lahan gambut. Selain lahan gambut, dataran tinggi juga pilihan alternatif lainnya dalam melakukan budidaya kelapa sawit. Dataran tinggi juga tersedia lebih banyak dan potensi konflik tata guna lahan relatif kecil.

Kelapa sawit adalah tanaman hutan yang dibudidayakan sehingga tanaman ini memiliki daya adaptasi dan respon yang baik terhadap kondisi lingkungan hidup, kultur teknis ataupun perlakuan yang diberikan. Kelapa sawit membutuhkan kondisi tumbuh yang baik agar potensi produksinya dapat dihasilkan secara maksimal. Kondisi lingkungan sebagai faktor eksternal merupakan faktor fisik disamping faktor internal seperti genetik, biotik, kultur teknis atau perlakuan yang diberikan.

Kelapa sawit merupakan salah satu komoditas ekspor non migas yang sangat penting artinya dalam perekonomian Indonesia. Sebagai salah satu komoditas perkebunan, kelapa sawit berperan dalam pembangunan nasional karena menghasilkan sumber devisa bagi negara. Selain itu kelapa sawit juga dapat meningkatkan pendapatan petani serta membuka lapangan kerja yang luas bagi masyarakat.

Permintaan global terhadap minyak goreng diperkirakan akan mencapai sekitar 240 juta ton pada tahun 2050, hampir dua kali konsumsi tahun 2008. Untuk memenuhi tambahan permintaan tersebut, merupakan anugerah bagi kelapa sawit, karena biaya produksi terendah dibanding minyak nabati lainnya. Kemajuan riset dan teknologi serta meningkatnya kesadaran akan kelestarian lingkungan diyakini akan membuat masa depan kelapa sawit Indonesia semakin prospektif. Perusahaan perkebunan kelapa sawit akan semakin terdorong untuk menerapkan teknologi terkini dalam pengembangan produksi kelapa sawit, disamping meningkatkan komitmennya menjaga lingkungan (Ditjenbun, 2014).

Meningkatnya permintaan terhadap minyak goreng tidak disertai dengan peningkatan perluasan areal penanaman kelapa sawit. Upaya peningkatan produksi kelapa sawit di Indonesia melalui perluasan areal dibatasi oleh ketersediaan lahan dan penerapan kultur teknis yang kurang efektif. Areal yang tersedia untuk pengembangan kelapa sawit tersebut umumnya adalah tanah kelas marginal (S3), yang memiliki kesuburan fisik dan kimia yang rendah. Bahkan perluasan areal penanaman kelapa sawit juga dilakukan pada ketinggian tempat diatas $600 \mathrm{~m}$ di atas permukaan laut (dpl).

Dibutuhkan kajian lanjutan tentang budidaya kelapa sawit pada dataran tinggi. Hal ini agar pemanfaatan lahan sesuai dengan peruntukannya dan dapat meningkatkan kesejahteraan khususnya petani. Selain itu budidaya kelapa sawit di dataran tinggi diharapkan dapat meminimalisisir adanya upaya deforestri hutan serta konflik sosial karena dilakukan jauh dari pemukiman penduduk

Penanaman kelapa sawit pada beberapa ketinggian tempat yang memiliki perbedaan suhu harian, menunjukkan pengaruh yang berbeda terhadap pertumbuhan tanaman kelapa sawit pada tanaman belum menghasilkan (TBM) dan tanaman menghasilkan (TM). Pada tanaman belum menghasilkan, pengamatan vegetatif berupa tinggi tanaman, panjang rachis, lebar dan tebal petiole menunjukkan hasil yang tidak berbeda nyata pada penanaman di dataran rendah maupun di dataran tinggi. Sedangkan pada tanaman menghasilkan, pengamatan vegetatif yaitu tinggi tanaman, panjang rachis, lebar dan tebal petiola menunjukkan hasil yang lebih tinggi pada penanaman di dataran tinggi bila dibandingkan dengan penanaman di dataran rendah ( Siregar et al, 2007).

Di daerah dataran tinggi suhu lebih rendah karena setiap kenaikan $100 \mathrm{~m}$ suhu menurun sekitar $0.6^{\circ} \mathrm{C}$. Suhu berpengaruh terhadap fisiologis tumbuhan antara lain bukaan stomata, laju penyerapan air dan nutrisi, fotosintesis dan respirasi. Suhu yang tinggi atau terlalu rendah akan menghambat pertumbuhan. Suhu minimum $\left( \pm 10^{\circ} \mathrm{C}\right)$ merupakan suhu terendah dimana tumbuhan masih dapat tumbuh. Suhu maksimum $\left(30^{\circ} \mathrm{C}\right.$ hingga $\left.39^{\circ} \mathrm{C}\right)$ merupakan suhu tertinggi dimana tumbuhan masih dapat tumbuh. Peningkatan suhu sampai titik optimum akan diikuti oleh peningkatan metabolisme tanaman (Wulan, 2012).

Kelapa sawit dapat tumbuh dengan baik pada dataran rendah di daerah tropis yang beriklim basah, yaitu sepanjang garis khatulistiwa yaitu $15^{\circ} \mathrm{LU}$ sampai $15^{\circ} \mathrm{LS}$. Di luar zona tersebut biasanya pertumbuhan tanaman kelapa sawit agak terhambat sehingga masa awal produksinya juga terhambat. Umumnya tanaman kelapa sawit tumbuh optimum pada dataran rendah dengan ketinggian 
200-500 $\mathrm{m}$ dari permukaan laut (dpl). Ketinggian lebih dari $600 \mathrm{~m}$ dpl tidak cocok untuk pertumbuhan tanaman kelapa sawit. Perbedaan ketinggian tempat akan mempengaruhi suhu, tingkat pencahayaan dan curah hujan pada tanaman kelapa sawit (Setyamidjaja, 1999).

Kelapa sawit yang diusahakan di dataran rendah yaitu $50 \mathrm{~m}$ dpl dan $368 \mathrm{~m}$ dpl rendemen minyaknya lebih tinggi jika dibandingkan dengan kelapa sawit yang dibudidayakan di dataran lebih tinggi yaitu $693 \mathrm{~m}$ dpl dan $865 \mathrm{~m}$ dpl. Hal ini disebabkan oleh intensitas radiasi matahari yang lebih tinggi di dataran rendah mengakibatkan laju akumulasi bahan kering ke dalam tandan buah segar juga lebih kuat jika dibandingkan dengan di dataran tinggi. Laju akumulasi bahan kering yang tinggi menstimulasi sintesis minyak di dalam TBS karena minyak pada hakekatnya berasal dari bahan kering hasil fotosintesis. Oleh karena itu, TBS yang dihasilkan di dataran rendah memiliki rendemen minyak yang jauh lebih tinggi jika dibandingkan dengan TBS yang dihasilkan di dataran tinggi ( Listia et al, 2015).

Penanaman kelapa sawit sampai dengan ketinggian 850 dpl pada kasus di Perusahaan Nusantara IV dalam dekade terakhir menjadi lebih dari $180 \mathrm{o}$ dari tahun sebelumya. Hal ini berkaitan dengan pemanasan global (global warming) maupun perubahan iklim (climate change). Oleh karena itu berdasarkan survei dan evaluasi kondisi lahan perusahan maka sudah dapat disarankan penanaman kelapa sawit sampai dengan elevasi ketinggian $850 \mathrm{~m}$ dpl (Lubis, 2008).

\section{Tujuan}

- Mengamati Produktivitas Kelapa Sawit pada dataran tinggi pada kelas lahan tidak sesuai besyarat (Kelas N1).

- Mengetahui sebaran produktivitas Kelapa Sawit pada dataran tinggi.

\section{PELAKSANAAN PENELITIAN}

\section{Tempat dan Waktu}

Penelitian ini dilaksanakan diperkebunan Kelapa Sawit Rakyat pada 4 Kecamatan dengan elevasi ketinggian tempat 416 (Kecamatan Gunung setimber), 434 (Kecamatan Siempat
Nempu Hilir), 655 (Kecamatan Siempat Nempu), dan 936 (Kecamatan Siempat Nempu Hulu) Mdpl pada Kabupaten Dairi Provinsi Sumatera Utara.

\section{Alat dan Bahan}

Bahan-bahan yang digunakan sebagai sampel adalah Tanaman Menghasilkan (TM) Kelapa Sawit milik rakyat dengan umur >5 tahun produksi.

Alat-alat yang digunakan adalah: 1) Meteranl, 2) Timbangan, 3) GPS, 4) Egrek, 5) Kamera 6) Alat tulis.

\section{Metode Penelitian}

Penelitian dilakukan di perkebunan kelapa sawit rakyat pada empat kecamatan dengan elevasi ketinggian tempat 416, 434, 655 dan 936 $\mathrm{m}$ dpl pada kabupaten Dairi provinsi Sumatera Utara. Penelitian ini menggunakan Rancangan Acak Kelompok (RAK) dengan metode survey lapangan. Pengamatan sampel tanaman kelapa sawit meliputi tinggi tanaman, diameter batang, produktivitas per luasan, indeks luas daun (ILD) dan indeks panen. Hasil data yang diperoleh dari lokasi kebun selanjutnya dianalisis menggunakan Analisis Varian (ANOVA) pada taraf 5\%. Hubungan antar varian pengamatan diuji menggunakan analisis regresi.

Alat yang digunakan dalam penelitian ini adalah GPS, meteran, timbangan, egrek, kamera, serta alat tulis. Bahan yang digunakan sebagai sampel adalah tanaman menghasilkan (TM) kelapa sawit milik rakyat dengan umur $>5$ tahun produksi.

Metode pengambilan sampel menggunakan metode SRS (simple random sampling) dengan ketentuan keragaman umur tanaman dan jenis tanah yang sama.. Tanaman yang dipilih merupakan tanaman sehat dan bukan tanaman sisipan. Lokasi titik tanam sampel dicatat (record) menggunakan GPS.

\section{HASIL DAN PEMBAHASAN}

\section{Hasil Yang Dicapai.}

Setelah dilakukan obsevasi langsung dari lapangan dan data skunder yang di peroleh dinas 
Pertanian setempat hasil penelitian sebagai berikut:
A. Luas Lahan Kelapa Sawit di Empat
Hasil pengamatan Luas lahan tanaman Kecamatan
B. Luas Tanaman Kelapa Sawit Belum menghasilkan kelapa sawit di empat kecamatan dengan luas yang berbeda selama 5 tahun yang telah berlalu dapat dilihat pada tabel 1 sebagai berikut :

Tabel 1. Perkembangan Luas lahan Tanaman Belum Menghasilkan (TBM) kelapa sawit di empat Kecamatan dari tahun 2013-2017.

\begin{tabular}{cccccc}
\hline Tahun/Kec. & $\begin{array}{c}\text { Siempat. } \\
\text { Nempu }\end{array}$ & Hulu & $\begin{array}{c}\text { S.N. } \\
\text { Hilir }\end{array}$ & $\begin{array}{c}\text { Gunung. } \\
\text { Sitimber }\end{array}$ & Rataan \\
\hline 2013 & 6.00 & 4.00 & 5.00 & 6.00 & $5.25 \mathrm{a}$ \\
2014 & 6.00 & 4.00 & 5.00 & 6.00 & $5.25 \mathrm{a}$ \\
2105 & 4.00 & 3.00 & 6.00 & 6.00 & $4.75 \mathrm{a}$ \\
2016 & 4.00 & 3.00 & 6.00 & 6.00 & $4.75 \mathrm{a}$ \\
2017 & 5.00 & 3.00 & 7.00 & 7.00 & $5.50 \mathrm{a}$ \\
\hline \multirow{2}{*}{20} & & 3.40 & & & \\
Rata-rata & $5.00 \mathrm{c}$ & $\mathrm{d}$ & $5.80 \mathrm{~b}$ & $6.20 \mathrm{a}$ & \\
\hline
\end{tabular}

Keterangan : Notasi huruf yang sama pada kolom yang sama berbeda tidak nyata pada taraf $5 \%$

Sumber : Analisa BPPTP Sumatera Utara

Dari table 1 dapat dilihat tanaman belum menghasilkan sejak tahun 2013 sampai 2017 mengalami perubahan perluasan yang tidak nyata namun sedikit perluasan dari tahun 2016 dengan luas TBM keempat kecamatan yang diteliti rata-rata 4.75 Ha ke 2017 menjadi ratarata $5.5 \mathrm{Ha}$.

Pada keempat kecamatan luas areal TBM kelapa sawit berdasarkan analisa statistic berbeda nyata $(\mathrm{p}<0.05)$ tetapi tidak terlalu luas, dimana Kecamatan Gunung Sitimber merupakan TBM paling luas rata-rata $6.2 \mathrm{Ha}$ Tabel 2. Perkembangan Luas Lahan Tanaman Menghasilkan (TM) kelapa sawit di empat Kecamatan dari tahun 2013-2017. sedangkan paling kecil di kecamatan Siempat Nempu Hulu dengan rata-rata $3.4 \mathrm{Ha}$, manakala Kecamatan Siempat Nempu dan Siempat Nempu Hilir berada keluasan ditengah rata-rata 5.0 dan 5.8 ha.

\section{Luas Tanaman Kelapa Sawi Menghasilkan}

Tanaman Kelapa sawit yang menghasilkan sejak tahun 2013 - 2017 untuk keempat Kecamatan dapat dilihat pada Tabel 2. 


\begin{tabular}{cccccc}
\hline Tahun/Kec. & $\begin{array}{c}\text { Siempat. } \\
\text { Nempu }\end{array}$ & Hulu & $\begin{array}{c}\text { S.N. } \\
\text { Hilir }\end{array}$ & $\begin{array}{c}\text { Gunung } \\
\text { Sitimber }\end{array}$ & $\begin{array}{c}\text { Rata- } \\
\text { rata }\end{array}$ \\
\hline 2013 & 8.00 & 17.00 & 11.00 & 6.00 & $\begin{array}{c}10.50 \\
\mathrm{a}\end{array}$ \\
2014 & 8.00 & 17.00 & 11.00 & 6.00 & $\begin{array}{c}10.50 \\
\mathrm{a}\end{array}$ \\
2105 & 7.00 & 16.00 & 15.00 & 4.00 & $\begin{array}{c}10.50 \\
\mathrm{a}\end{array}$ \\
& & & & & 10.50 \\
2016 & 7.00 & 16.00 & 15.00 & 4.00 & $\mathrm{a}$ \\
2017 & 8.60 & 18.20 & 7.10 & 8.70 & $\begin{array}{c}10.65 \\
\mathrm{a}\end{array}$ \\
\hline & & 16.84 & & & \\
Rata-rata & $7.72 \mathrm{c}$ & $\mathrm{a}$ & $11.82 \mathrm{~b}$ & $5.74 \mathrm{c}$ & 10.53 \\
\hline
\end{tabular}

Keterangan : Notasi huruf yang sama pada kolom yang sama berbeda tidak nyata pada taraf $5 \%$

Dari table 2 dapat dilihat tanaman (TM) menghasilkan sejak tahun 2013 sampai 2017 mengalami perubahan perluasan yang tidak nyata ( $\mathrm{p}>0.05$ ) dengan luas TM keempat kecamatan yang diteliti rata-rata 10.5 ha sejak 2013 sampai dengan 2017.

Berdasarkan hasil analisa statistic bahwa tanaman menghasilkan kelapa sawit di empat kecamatan tanaman yang menghasilkan paling luas di kecamatan Siempat Nempu Hulu ratarata 16.84 Haberbeda nyata $(p<0.05$ terhadap kecamatan lain dan paling sedikit dihasilkan di Kecamatan Gunung Sitimber rata-rata $5.74 \mathrm{Ha}$, tetapi luas berbeda tidak nyata dengan kecamatan Siempat nempu (7.72 Ha) dan berbeda nyata terhadap Kecamatan Hulu dan Hilir.

\section{Luas Tanaman Kelapa Sawit Tidak Menghasilkan (TTM)}

Luas Lahan tanaman Kelapa sawi yang tidak menghasilkan di empat kecamatan hanya diperoleh data pada Kecamatan Siempat Nempu saja terdapat tanaman yang tidak menghasilkan lagi rata-rata $02 \mathrm{Ha}$ manakala kecamatan lain tidak ada tanaman yang tidak menghasilkan lagi.

Untuk membedakan luas lahan di keempat kecamatan baik TBM, TM. Dan TTM dapat digambarkan pada Gambar 1.

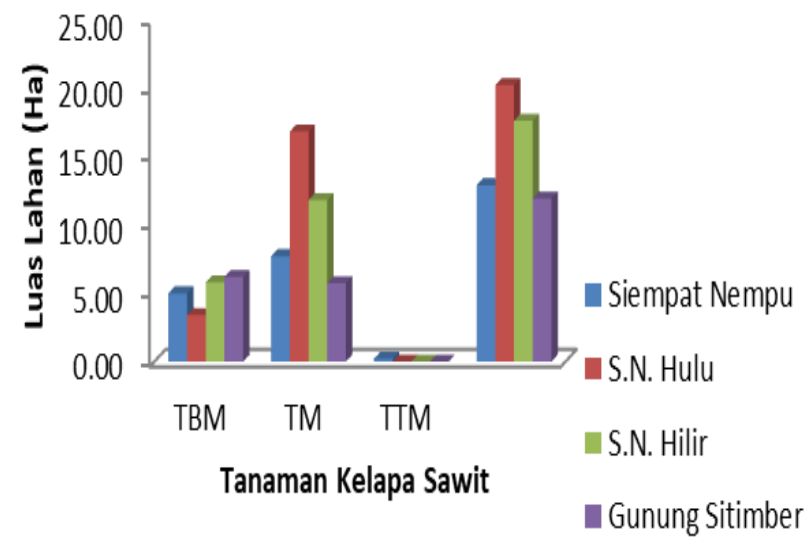

Gambar 1. Histogram Rata-rata Tanaman

Kelapa Sawit (Ha) di Empat Kecamatan 


\section{B. Produksi Tanaman Kelapa Sawit di Empat Kecamatan.}

Hasil analisa statistic bahwa produksi kelapa sawit di empat Kecamatan menunjukkan berbeda nyata, untuk jelanya dapat dilihat pada Tabel 3.
Perkembangan produksi kelapa sawit di empat kecamatan sejak 2013 sampqi 2017 berdasarkan hasil data dari Propinsi bahwa sejak tahun 2013 dengan rata-rata produksi 19.5 ton/ha meningkat sampai tahun 2016 secara perlahan tetapi pada tahun 2017 meningkat 100 $\%$ dengan produksi rata-rata 40.08 ton/ha.

Tabel 3. Hasil Anlisa Produksi kelapa sawit (ton/ha/tahun) diempat kecamatan sejak tahun 2013 2017.

\begin{tabular}{cccccc}
\hline & Siempat & $\begin{array}{c}\text { S.N. } \\
\text { Tahun/Kecamatan }\end{array}$ & $\begin{array}{c}\text { S.N. } \\
\text { Hilir }\end{array}$ & $\begin{array}{c}\text { Gunung } \\
\text { Sitimber }\end{array}$ & $\begin{array}{c}\text { Rata- } \\
\text { rata }\end{array}$ \\
\hline 2013 & 17.00 & 31.00 & 17.00 & 13.00 & $\begin{array}{c}19.50 \\
\mathrm{~b}\end{array}$ \\
2014 & 17.00 & 31.00 & 17.00 & 13.00 & $\begin{array}{c}19.50 \\
\mathrm{~b}\end{array}$ \\
2105 & 17.00 & 35.00 & 20.00 & 10.00 & $\begin{array}{c}20.50 \\
\mathrm{~b}\end{array}$ \\
2016 & 17.00 & 35.00 & 20.00 & 10.00 & $\begin{array}{c}20.50 \\
\mathrm{~b}\end{array}$ \\
& & & & & 40.08 \\
2017 & 40.10 & 75.20 & 24.00 & 21.00 & $\mathrm{a}$ \\
\hline & & 41.44 & & & \\
\hline Rata-rata & $21.62 \mathrm{~b}$ & $\mathrm{a}$ & $19.60 \mathrm{~b}$ & $13.40 \mathrm{~b}$ & \\
\hline
\end{tabular}

Keterangan : Notasi huruf yang sama pada kolom yang sama berbeda tidak nyata pada taraf $5 \%$

Sumber Data: Analisa BPPTP Sumatera Utara (2018).

Dari Tabel 3. Dapat diketahui bahwa produksi kelapa sawit dari lapanagan dari hasil analisa statistic menunjukkan berbeda nyata ( $\mathrm{p}$ $<0.05)$ dimana kecamatan Siempat Nempu Hulu merupakan produksi paling tinggi dengan rata-rata 41.44 ton/ha berbeda nyata dengan produksi ketiga Kecamatan lainnya, manakala kecamatan Siempat nempu, Siempat nempu Hilir dan Gunung sitimber merupakan produksi yang berbeda tidak nyata $(p>0.05)$ dengan produksi antara 13.4 sampai 21.62 ton/ha. Dibandingkan dengan produksi kelapa sawit rata-rata untuk tiap keluarga dapat dilihat pada Tabel 4
Rata-rata Produksi/kk/tahun berdasarkan analisa statistic diperoleh ada perbedaan yang nyata yang mana kecamatan Siempat Nempu Hulu mempunyai produksi/kk paling tinggi dengan rata-rata $1.604 .44 \mathrm{~kg} / \mathrm{kk} / \mathrm{tahun}$ namun berbeda tidak nyata dengan kecamatan (SN Hilir) rata-rata $1213.68 \mathrm{~kg} / \mathrm{kk} / \mathrm{tahun}$. Dibandingkan dengan kecamatan Siempat Nempu rata-rata $802.71 \mathrm{~kg} / \mathrm{kk} /$ tahun merupakan produksi paling rendah dengan berbeda tidak nyata dengan SN Hilir, Siempat Nempu dan Gunung sitimber. 
Tabel 4. Hasil Anlisa Produksi kelapa sawit (kg/kk/tahun) diempat kecamatan sejak tahun 2013 2017.

\begin{tabular}{cccccc}
\hline $\begin{array}{l}\text { Tahun/ } \\
\text { Kecamatan }\end{array}$ & $\begin{array}{c}\text { Siempat. } \\
\text { Nempu }\end{array}$ & $\begin{array}{c}\text { S.N. } \\
\text { Hulu }\end{array}$ & $\begin{array}{c}\text { S.N. } \\
\text { Hilir }\end{array}$ & $\begin{array}{c}\text { Gunung } \\
\text { Sitimber }\end{array}$ & $\begin{array}{c}\text { Rata- } \\
\text { rata }\end{array}$ \\
\hline 2013 & 680.00 & 1148.15 & 1000.00 & 866.67 & $\begin{array}{c}923.70 \\
\mathrm{~b}\end{array}$ \\
2014 & 680.00 & 1148.15 & 1000.00 & 866.67 & $\begin{array}{c}923.70 \\
\mathrm{~b}\end{array}$ \\
2105 & 680.00 & 1296.30 & 1111.11 & 666.67 & $\begin{array}{c}938.52 \\
\mathrm{~b}\end{array}$ \\
2016 & 680.00 & 1296.30 & 1111.11 & 666.67 & $\begin{array}{c}938.52 \\
\mathrm{~b}\end{array}$ \\
2017 & 1293.55 & 3133.33 & 1846.15 & 2625.00 & $\begin{array}{c}2224.51 \\
\mathrm{a}\end{array}$ \\
\hline & & & & & \\
\hline Rata-rata & $802.71 \mathrm{~b}$ & $1604.44 \mathrm{a}$ & $1213.68 \mathrm{ab}$ & $1138.33 \mathrm{~b}$ & \\
\hline
\end{tabular}

Keterangan : Notasi huruf yang sama pada kolom yang sama berbeda tidak nyata pada taraf $5 \%$.

Untuk membedakan produksi tanaman kelapa sawit berdasarkan empat kecamatan dapat dilihat pada Gambar 2.

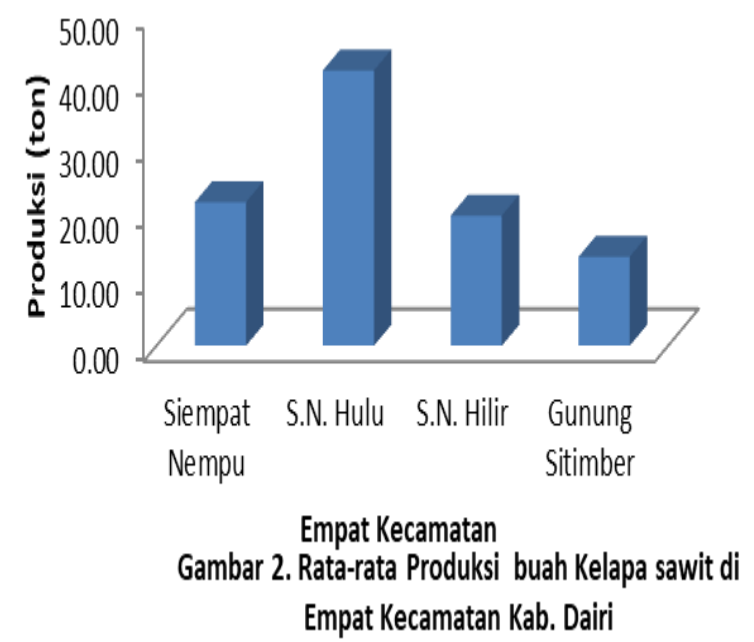

Dibandingkan kepada keluasan lahan tanaman kelapa sawit yang digunakan petani dengan hasil tanaman yang diperoleh memunyai korelasi yang positif dengan semakin luas lahan yang diperoleh memberi hasil yang semakin tinggi, berdasarkan persamaan linier $\hat{\mathrm{Y}}=2.237$ $\mathrm{L}+0.451$ dengan $\mathrm{r}=0.91$ dapat dilihat pada gambar 3 . 


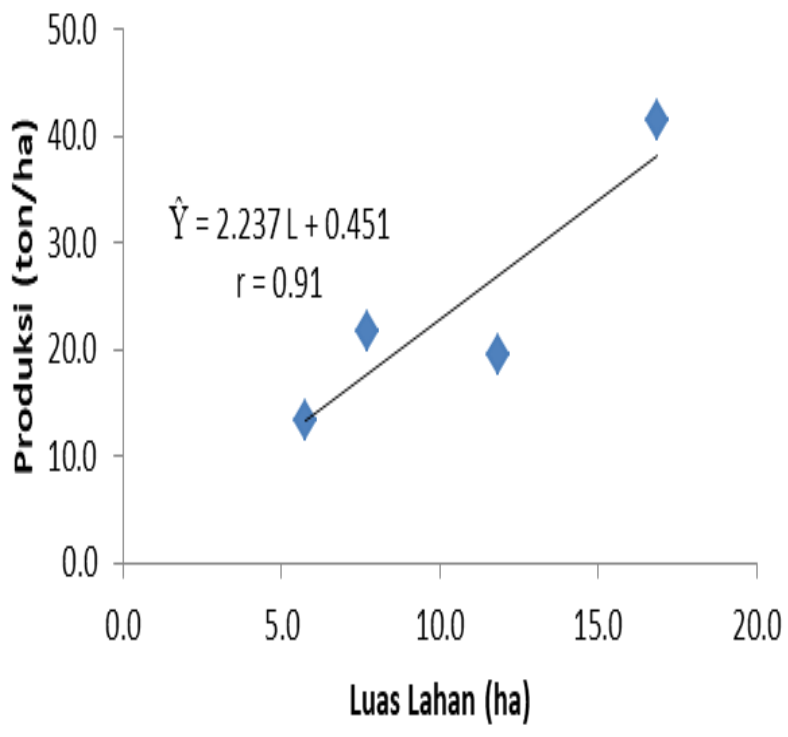

\section{Gambar 3. Korelasi Rata-rata Keluasan Tanah pengaruhnya terhadap produksi (ton/ha)}

\section{Pembahasan}

Berdasarkan luas tanaman kelapa sawit sejak tahun 2013 sampai dengan 2017 berdasarkan hasil analisa statistik menunjukkan perbedaan yang tidak nyata ini menunjukkan hanya sedikit atau hampir tidak ada penambahan atau melakukan pembukaan lahan untuk penanaman kelapa sawit. Hal ini disebabkan karena dengan hasil yang sedikit akibat luas lahan kecil dan daerah kecamatan yang sangat jauh kota, sehingga di daerah ini tidak dilakukan pembukaan pabrik untuk mengolah buah sawit ini. Petani yang mempunyai ladang kelapa sawit enggan penanaman dalam jumlah yang luas.

Petani di empat kecamatan pendapatannya utama adalah petani tanaman pangan, dan palawija dan jika bergantung kepada produksi sawit adalah sangan merugikan, hal-hal yang umum dipakai oleh pekebun sawit tidak meluaskan arealnya disebabkan karena: pabrik PKS terlalu jauh dari areal sehingga keuntungan yang akan diperolh adalah kecil. Dilain masalah adalah sektor pengangkutan, dimana motor anggutan tidak semua yang mau dijadikan angkutan buah sawit, malahan angkutan yang khusus. Pemanenan memerlukan kemahiran yang khusus sehingga tercapai target panen/hari, keterlambatan panen tidak diangkat oleh mobil pengangkutan buah.

Luas lahan baru (TBM) terlihat lebih sedikit dibandingkan tanaman kelapa sawit menghasilkan. Pertanian kelapa sawit di empat kecamatan adalah sedikit dan baru mula bertanam, hal ini terlihat bahwa tanaman tidak menghasilkan (TTM) tidak ada kecuali kecamatan siempat Nempu (rata-rata 0.2 ha) saja.

Berbeda daerah kecamatan yang dijadikan penelitian terlihat kemampuan dari peneliti juga beragam tetapi penuh semangat, hal ini disebabkan oleh beberapa hal antara lain: topografi yang beragam, susah untuk mendapatkan bibit dan pupuk, selain itu adalah faktor lingkungan'

Produksi buah kelapa sawit di empat kecamatan masing-masing setelah dianalisa statistik menunjukkan perbedaan yang nyata dengan produksi paling tinggi di kecamatan Siempat nempu baik produksi/ha maupun produksi setiap kepala rumah tangga (KK). Hasl ini disebabkan adanya beberapa faktor yang mempengaruhinya salah satu diantaranya antara lain luas lahan, seperti yang terlihast pada Gambar 3. Dari gambar 3 menunjukkan bahwa dengan semakin luasnya lahan pada empat kecamatan memberi hasil yang semakin tinggi. Pemeliharaan tanaman kelapa sawit di empat kecamatan tidak melakukan pemupukan, dimana usaha peningkatan hasil telah banyak upaya pemerintah untuk meningkatkan produksi subsektor perkebunan misalnya melalui intensifikasi, ekstensifikasi, diversifikasi dan rehabilitasi lahan. Salah satu 
tanaman perkebunan yang bernilai ekonomis yaitu tanaman kelapa sawit. Peningkatan luas tanaman dan produksi tanaman kelapa sawit tidak terlepas dari semakin baiknya pasar komoditi ini di pasar luar negeri, dan juga karena adanya kenaikan harga (Ridho, 2018).

Ahyari (2004) menyatakan produksi merupakan kegiatan yang dapat menimbulkan tambahan manfaat dan penciptaan faedah baru. Faedah atau manfaat tersebut terdiri dari faedah bentuk, waktuk, tempat, serta kombinasi dari faedah-faedah tersebut diatas. Apabila terdapat suatu kegiatan yang dapat menimbulkan manfaat baru atau mengadakan penambahan dari manfaat yang sudah ada maka kegiatan tersebut disebut sebagai kegiatan produksi.

Sugiarto et. al. (2007) menyatakan bahwa produksi adalah suatu kegiatan yang mengubah input menjadi output. Kegiatan tersebut dalam ekonomi biasa dinyatakan dalam fungsi produksi. Analisis terhadap kegiatan produksi perusahaan dikatakan berada dalam jangka pendek apabila sebagian dari faktor produksi dianggap tetap jumlahnya (fixed input) sedangkan dalam jangka panjang semua faktor produksi dapat mengalami perubahan yang artinya bahwa setiap factor produksi dapat ditambah jumlahnya kalau memang diperlukan.

Hal ini juga tidak terlepas dari kesuburan tanah masing-masing kecamatan Kesuburan tanah secara umum kaya dengan bahan organic dan baha organic merupakan hasil perombakan yang dilakukan mikroorganik. Dengan keberadaan microorganism mampu memperbaiki sifat fisik, kimia dan biologi tanah. Dengan kondisi tanah yang baik akan menciptakan lingkungan tumbuh yang sesuai bagi pertumbuhan tanaman, yaitu tercermin pada penampilan tanaman. Walaupun genotifnya sama, dalam lingkungan yang berbeda akan berbeda pula penampilan suatu tanaman. Adapun peranbahan organik terhadap sifat fisik tanah adalah menjadikan tanah berstruktur remah, demikianpula dengan aerasi tanah menjadi lebih baik karena porositas atau ruang pori bertambah.Aerasi tanah berhubungan dengan kandungan air, gas $\mathrm{O} 2, \mathrm{~N} 2$ dan $\mathrm{CO} 2$ didalam tanah, yangsangat berpengaruh terhadap perkembangan akar dan kehidupan mikroorganisme tanah. Akibat dari kenyataan bahwa pertumbuhan tanaman yang sangat meningkat memerlukan lebih banyak pengambilan nitrogen. Tetapi, kehilangan nitrogen meningkat bila kemampuan tanah dalam imobilisasi terlampaui (Arif, 2005).

Kondisi kesuburan tanah yang kaya akan bahan organic diikuti dengan keberadaan mikroorganisme memacu untuk membuat terobosan dengan menjaga kesuburan tanah, memperbaiki struktur tanah, memperkaya bahan makanan dalam tanah, dan menetralisir kimia atau racun dalam tanah. (Kanti, 2005).

\section{KESIMPULAN DAN SARAN}

\section{Kesimpulan}

1. Ketinggian penanaman kelapa sawit sampai $936 \mathrm{~m}$ dpl (Siempat nempu Hulu) di empat kecamatan tidak memberikan pengaruh produksi yang dihasilkan dibandingkan dengan $434 \mathrm{~m}$ dpl (Siempat nempu)

2. Sebaran produksi kelapa sawit di empat kecamatan tidak merata disebabkan karena kawasan penanaman berbukit dan jauh dari pasar.

\section{DAFTAR PUSTAKA}

Ahyari, Agus. 2004. Manajemen Produksi: Perencanaan Sistem Produksi. Yogyakarta: BPFE UGM

Arif Ghazali Ritonga. Abdul Rauf. (2016). Karakteristik Biologi Tanah pada Berbagai Penggunaan Lahan di Sub DAS Petani Kabupaten Deli Serdang Sumatera Utara. Fakultas Pertanian, USU, Medan. Jurnal Agroekoteknologi.Vol.4. No.3 pp. 1983 $-1988$

Ditjenbun. Kementerian Pertanian. 2014. Pedoman Budidaya Kelapa Sawit (Elaeis guineensis) Yang Baik. ISBN 978-979-1109-67-3

Kanti, A., 2005, Actinomycetes Selulolitik dari Tanah Hutan Taman Nasional Bukit Duabelas, Jambi, Bidang Mikrobiologi, Pusat Penelitian Biologi, Lembaga Ilmu Pengetahuan Indonesia (LIPI), 6 (2), 85-89.

Listia, Eka., Indradewa, Didik., dan Tarwaca, Eka. Pertumbuhan Produktivitas dan Rendemen Minyak Kelapa Sawit di Dataran Tinggi. 2015. Jurnal Ilmu Pertanian.18(2): 77-83. Universitas Gadjah Mada, Yogyakarta 
Lubis, Adlin U. 2008. Kelapa sawit (Elaeis guineensis Jacq) di Indonesia Edisi 2. Pusat Penelitian Kelapa Sawit.

Ridho. A. 2018. Faktor-faktor yang mempengaruhi Produksi Tanaman Kelapa Sawit di Aceh Timur. Jurnal Samudra Ekonomika Vol 2. No. 1 April 2018.

Siregar, Hasril Hasan., G. Simangunsong, Eka Listia, Taufiq Caesar Hidayat and Iman Yani Harahap. 2007. Oil Palm Performance in Higher Altitude (Case of North Sumatera, Indonesia). Proceeding PORIM International Palm Oil Conference. Malaysia.

Setyamidjaja, D. 1999. Budidaya Sawit. UT. Jakarta.

Sugiarto et. al. 2007. Ekonomi Mikro: Sebuah Kajian Komprehensif. Jakarta: PT. Gramedia Pustaka Utama

Wulan. S. 2012. Faktor Lingkungan Yang Mempengaruhi Pertumbuhan Tanaman. (online), (http://myrealact. Diakses Agustus 2018) 